Gut, 1974, 15, 189-193

\title{
Evaluation of colloidal bismuth (De-Nol) in the treatment of duodenal ulcer employing endoscopic selection and follow up
}

\author{
P. R. SALMON, P. BROWN, R. WILliaMS, AND A. E. READ \\ From the University of Bristol, Department of Medicine, Bristol Royal Infirmary, Bristol
}

SUMmARY A double-blind, placebo-controlled trial of colloidal bismuth (De-Nol) was performed on 20 patients with active duodenal ulceration employing endoscopic selection and follow up after a treatment period of 28 days. By these means it was shown that healing of ulcers was significant in those patients treated with the active compound. In addition a greater number $(9 / 10)$ of patients treated with colloidal bismuth showed symptomatic improvement than those receiving placebo (6/10) but this difference did not reach statistical significance. The results of endoscopic and symptomatic assessment of the patients receiving colloidal bismuth were in complete agreement although there was a poor correlation between these results in those receiving the placebo. This supports the results from a previous study that endoscopic assessment of duodenal ulcer healing provides a more objective assessment than do clinical methods.

Antacids and to a lesser extent anticholinergic drugs have dominated the medical treatment of peptic ulcer for over 20 years whilst antacids themselves have been in wide use for much longer (Sippy, 1915).

Although there is incontrovertible evidence that antacids are superior to placebo in relieving the symptoms of peptic ulcer (Lawrence, 1952; Doll, 1964) no effect on the rate of ulcer healing has been demonstrated in well controlled trials (Doll, Price, Pygott, and Sanderson, 1956; Baume and Hunt, 1969). There are moreover significant side effects when potent antacids (sodium bicarbonate, calcium carbonate, magnesium oxide) are used in pharmacological doses to neutralize gastric juice (Burnett, Commons, Albright, and Howard, 1949; Bleifer, Belsky, and Bleifer, 1959; Randall, Cohen, Spray, and Rossmeisl, 1964; Stiel, Mitchell, Radcliff, and Piper, 1967).

The situation is less satisfactory in the case of anticholinergic drugs. Although an optimum effective dose (sufficient to cause side effects) will reduce the basal, postprandial, and peak acid output, intragastric acidity throughout 24 hours in patients eating a bland diet is not affected (Lennard-Jones, 1961). Numerous controlled trials have failed to produce consistent evidence that anticholinergics Received for publication 29 November 1974. either promote healing or prevent relapses in patients with duodenal ulcer (Lennard-Jones, 1961; Melrose and Pinkerton, 1961 ; Kaye, Rhodes, Beck, Smeetnam, Davies, and Evans, 1970; Sun and Ryan, 1970).

During the past 10 years a large number of drugs with a very wide range of pharmacological action have been introduced for the treatment of gastric and duodenal ulcer. Clinical studies have shown some of them to be effective in ulcer therapy although in the majority of cases the studies have been uncontrolled. Their mode of action has been explained as altering gastric blood flow and motility via a corticohypothalamic action, eg, sulpiride (Albot and Boisson, 1969) and chlorbenzoxamine (Passeri, 1960); as inhibiting pepsin, eg, amylopectin sulphate (Sun and Ryan, 1970); as inhibiting the release of antral gastrin, eg, oxethazine (Farrar and Seifter, 1962); as decreasing gastric epithelial-cell extrusion and increasing mucus production, eg, carbenoxolone sodium (Brown et al, 1972b) and possibly BX-24 (Calcraft, Rhodes, Cross, and Hall, 1973); as altering cellular metabolism of the gastric mucosa, eg, proglumide (Borellini and Milvio, 1969) and geranyl farnesylacetate (Newcombe, Stone, and Richardson, 1970); and as an ulcer-insulating mechanism together with antipepsin activity, eg, colloidal bismuth compounds (Marks and Bank, 
1973). There are in addition a number of untested compounds that offer promise on theoretical grounds, eg, $\mathrm{H}_{2}$ receptor antagonists (Wyllie, Ealding, Hesselbo, and Black, 1973).

The aims of peptic ulcer therapy are relief of symptoms, ulcer healing, and prevention of relapse. Although it is relatively easy to assess relief of symptoms, duodenal ulcer healing has previously been assessed solely by radiological criteria. It is now clear that many of the conflicting results of clinical trials are partly due to the difficulties of interpreting the radiological appearance of the duodenal bulb in chronic duodenal ulcer (Brown, Salmon, Burwood, Knox, Clendinnen, and Read, 1973), and to the inaccuracy of symptoms as a guide to the presence or absence of a duodenal ulcer crater (Brown et al, 1972b; Salmon, 1973).

Fibreoptic duodenoscopy now offers a safe, reproducible, and objective method not only of selecting patients for clinical drug trials with a proven and defined ulcer crater but of following up these patients for evidence of ulcer healing (Salmon, Brown, Htut, and Read, 1972; Brown et al, 1972b).

Stable bismuth salt complexes differ from bismuthcontaining antacids in that they combine with proteins to form a chelate at acid $\mathrm{pH}$ rather than by neutralizing gastric acid secretion. It has been suggested that they have an affinity for granulation tissue (as in a necrotic ulcer base) and also by a similar chelating action that they possess pepsinbinding properties. Studies in vitro support this latter concept.

One of these compounds, tripotassium dicitrato bismuthate (De-Nol), has been used in a number of uncontrolled studies and in each case the clinical impression was that the compound was effective not only in relieving symptoms of both gastric and duodenal ulcers in two to nine days but also in promoting healing after four to eight weeks (Paullus, 1966; Weiss and Kallmeyer, 1968; Sobotka, 1970; Lanza, 1970).

A recent double-blind, placebo-controlled study of the related compound bismuth citropeptideconfirmed the effectiveness of colloidal bismuth in the treatment of peptic ulcer (Marks and Bank, 1973). In addition a recent controlled study has shown that tripotassium dicitrato bismuthate (De-Nol) promoted the healing of stress-resistant gastric ulcer in rats (Wilson, 1973).

In view of the promising nature of colloidal bismuth compounds and their virtual freedom from side effects we have performed a double-blind study of tripotassium dicitrato bismuthate (De-Nol) in the treatment of duodenal ulcer, employing fibreduodenoscopy in the selection and follow up of patients.

\section{Method of Study}

Patients with clinical and radiological evidence of a duodenal ulcer were submitted to duodenoscopy. The examination procedure has already been described (Salmon et al, 1972). A forward-viewing gastroduodenoscope was employed for examination of the duodenal bulb in all cases, supplemented where necessary by a lateral-viewing instrument. The instrument that gave the better view was used in the subsequent follow-up examination.

Ulcers were recorded photographically and their size was assessed by reference to the superior duodenal fold. Failing this, a calibrating instrument or the opened blades of biopsy forceps were employed (Brown et al, 1972b). Patients with an endoscopically visible duodenal ulcer without evidence of gastric ulceration and under the age of 65 were admitted to the trial.

A pilot study was performed beforehand on five healthy volunteers treated with $50 \mathrm{ml}$ De-Nol daily for seven days to establish the effect of De-Nol on acid base balance. Patients were randomized and allocated either to a 28-day course of tripotassium dicitrato bismuthate (De-Nol), $10 \mathrm{ml}$ diluted with $15 \mathrm{ml}$ water six times daily (on waking, half an hour before and two hours after meals), or to a placebo mixture having the same appearance, smell, and taste.

Patients were advised to take antacids only for symptomatic relief and not to take the compound with milk. These measures were designed to maintain the low gastric $\mathrm{pH}$ necessary for the action of colloidal bismuth compound. Patients were advised and encouraged to continue their normal daily routine without dietary restrictions.

Progress was assessed symptomatically and endoscopically at 28-32 days. Symptomatic assessment was based on the frequency and severity of pain or discomfort, change of symptoms, and consumption of antacids. Other factors such as time off work, appetite, and weight were also recorded and were taken into account in symptomatic assessment.

\section{Results}

Twenty-one patients were admitted to the trial. One patient, however, was withdrawn before commencing treatment because he was judged to be an unreliable historian. Of 20 patients completing the study, there were 10 treated with the active compound and 10 with placebo (table I). There were 15 males and five females (three in the active group, two in the placebo group). The average length of history was 13 years in the active group, $9 \cdot 2$ years in the placebo group. 


\begin{tabular}{|c|c|c|c|c|c|c|c|}
\hline \multicolumn{4}{|c|}{ Bismuth Compound $(n=10)$} & \multicolumn{4}{|c|}{ Placebo $(n=10)$} \\
\hline Patient & $\operatorname{Sex}$ & Age $(y r)$ & $\begin{array}{l}\text { Length of } \\
\text { History }\end{array}$ & Patient & $\operatorname{Sex}$ & Age (yr) & Length of History \\
\hline $\begin{array}{l}\text { G.T. } \\
\text { J.W. } \\
\text { R.F. } \\
\text { E.W. } \\
\text { R.F. } \\
\text { D.M. } \\
\text { H.V. } \\
\text { A.K. } \\
\text { H.J. } \\
\text { M.P. }\end{array}$ & $\begin{array}{l}\mathbf{M} \\
\mathbf{F} \\
\mathbf{M} \\
\mathbf{M} \\
\mathbf{M} \\
\mathbf{M} \\
\mathbf{M} \\
\mathbf{F} \\
\mathbf{M} \\
\mathbf{F}\end{array}$ & $\begin{array}{l}64 \\
44 \\
45 \\
41 \\
47 \\
52 \\
51 \\
43 \\
40 \\
49\end{array}$ & $\begin{array}{r}30 \mathrm{yr} \\
3 \mathrm{yr} \\
15 \mathrm{yr} \\
2 \mathrm{yr} \\
25 \mathrm{yr} \\
20 \mathrm{yr} \\
20 \mathrm{yr} \\
10 \mathrm{yr} \\
1 \mathrm{mth} \\
6 \mathrm{yr}\end{array}$ & $\begin{array}{l}\text { D.H. } \\
\text { A.M. } \\
\text { R.T. } \\
\text { C.D. } \\
\text { G.N. } \\
\text { A.H. } \\
\text { G.K. } \\
\text { A.J. } \\
\text { R.J. } \\
\text { M.W. }\end{array}$ & $\begin{array}{l}\mathbf{F} \\
\mathbf{F} \\
\mathbf{M} \\
\mathbf{M} \\
\mathbf{M} \\
\mathbf{M} \\
\mathbf{M} \\
\mathbf{M} \\
\mathbf{M} \\
\mathbf{M}\end{array}$ & $\begin{array}{l}47 \\
46 \\
36 \\
58 \\
45 \\
40 \\
47 \\
62 \\
64 \\
25\end{array}$ & $\begin{array}{l}4 \mathrm{yr} \\
1 \mathrm{yr} \\
3 \mathrm{mth} \\
30 \mathrm{yr} \\
5 \mathrm{yr} \\
1 \mathrm{yr} \\
10 \mathrm{yr} \\
21 \mathrm{yr} \\
12 \mathrm{yr} \\
7 \mathrm{yr}\end{array}$ \\
\hline Mean & & $47 \cdot 6$ & $13 \mathrm{yr}$ & Mean & & $47 \cdot 0$ & $9.2 \mathrm{yr}$ \\
\hline
\end{tabular}

Table I Details of patients admitted to trial

All 20 patients attended for follow-up examination and no patient failed to take the prescribed medicine, although this might have been expected since the slight ammoniacal odour (signifying that the compound is correctly buffered) might have discouraged patients from taking it. Several patients noted blackening of their stools but were warned to expect this. Patients were not asked routinely whether they noted this effect or not.

\section{SYMPTOMATIC ASSESSMENT}

All patients admitted to the trial presented with dyspepsia of varying severity and duration (table I). No patients were admitted following a haematemesis with dyspepsia as in a previous study (Brown et al, 1972). Nine out of 10 patients in the active group showed improvement in symptoms at $\mathbf{2 8 - 3 2}$ days as compared with six out of 10 in the placebo group (table II). This difference is not statistically significant.

\begin{tabular}{lll}
\hline Stage of Treatment & \multicolumn{2}{l}{ Treatment Group } \\
\cline { 2 - 3 } & Colloidal Bismuth & Placebo \\
\hline $28-32$ days & $9 / 10$ & $6 / 10$ \\
\hline
\end{tabular}

Table II Number of patients showing symptomatic improvement during treatment

$x^{2}=2 \cdot 14$ not significant $(\mathrm{P}<0.10)$

\section{ENDOSCOPIC ASSESSMENT}

There was a statistically significant difference $(P<0.05)$ in the number of patients showing endoscopic evidence of ulcer healing at 28-32 days in the colloidal bismuth group (De-Nol) (nine out of 10) compared with the placebo group (three out of 10) (table III).

In addition, when evidence of healing (ulcer size

\begin{tabular}{lll}
\hline Stage of Treatment & \multicolumn{2}{l}{ Treatment Group } \\
\cline { 2 - 3 } & Colloidal Bismuth & Placebo \\
\hline $28-32$ days & $9 / 10$ & $3 / 10$ \\
\hline
\end{tabular}

Table III Number of patients showing endoscopic improvement during treatment

$x^{2}=5.21(0.05>$ P $>0.01)$

diminished by more than $50 \%$ ) was compared with complete healing (duodenal bulb either completely normal or scarred but without endoscopic evidence of ulceration) seven out of eight (87.5\%) completely healed ulcers were in the colloidal bismuth (De-Nol) group and only one out of eight $(12.5 \%)$ was in the placebo group (table IV). This difference is highly significant $(P<0.01)$.

\begin{tabular}{lll}
\hline Stage of Treatment & \multicolumn{2}{l}{ Treatment Group } \\
\cline { 2 - 3 } & Colloidal Bismuth & Placebo \\
\hline $28-32$ days & $7 / 8$ & $1 / 8$ \\
\hline
\end{tabular}

Table IV Number of patients showing complete

healing (endoscopy) during treatment

$x^{2}=9.00$ highly significant $(\mathrm{P}<0.01)$

A comparison of symptoms and endoscopic findings is shown in table $\mathrm{V}$. Three out of seven $(43 \%)$ patients in the placebo group showed evidence of symptomatic improvement in spite of an ulcer crater being demonstrated by endoscopy at $28-32$ days. In both treatment groups, however, endoscopic healing was associated with improvement of symptoms.

\section{SIDE EFFECTS}

No change in acid-base balance (arterial $\mathrm{pH}$, 


\begin{tabular}{|c|c|c|c|c|c|c|c|}
\hline \multirow[b]{3}{*}{ Endoscopy } & \multicolumn{7}{|c|}{ Treatment Group } \\
\hline & \multicolumn{3}{|c|}{ Active (De-Nol) } & \multicolumn{4}{|l|}{ Placebo } \\
\hline & \multirow{2}{*}{\multicolumn{3}{|c|}{ Symptoms }} & \multicolumn{2}{|l|}{ Healing } & \multicolumn{2}{|c|}{ No Change } \\
\hline & & & & & & & \\
\hline & Imprcved & No change & Improved No Change & Improved & No Change & Improved & No Change \\
\hline At $28-32$ days & 8 & $\mathbf{0}$ & Improved Improved & 3 & $\mathbf{0}$ & 3 & 4 \\
\hline
\end{tabular}

Table V Comparison of symptoms and endoscopic findings in the two groups of patients

$\mathrm{PaCo}_{2}$, base excess, plasma bicarbonate, standard bicarbonate) was found in five healthy subjects (age range 25-35) treated with $50 \mathrm{ml}$ colloidal bismuth compound (De-Nol) daily for seven days. The amount of citrate present in the recommended dose for treating duodenal ulcers (up to $60 \mathrm{ml}$ daily) is not sufficient to expect any measurable change in acid-base balance. No patient in the study had severe renal failure where the renal handling of base might be defective.

No adverse side effects were noted by any patients. Blackening of the stools was noted by some and a slight ammoniacal smell by others, but was not considered sufficiently unpleasant to prevent any subject taking the prescribed dose.

\section{Discussion}

Trials of drugs for treating duodenal ulcer aim to assess relief of symptoms, ulcer healing, and prevention of relapse. In the past it has been difficult to assess ulcer healing since radiological criteria are not always reliable in evaluating the chronically deformed duodenal bulb. This may explain the different results quoted from centres evaluating the same drug.

In a prospective study of duodenoscopy, radiology, and surgery in the assessment of duodenal ulcer, performed within five days on $\mathbf{4 3}$ patients, radiology was accurate in 36 out of 43 cases (83\%) whilst endoscopy was accurate in 40 out of $43(93 \%)$. With both examinations together the pick-up rate was $98 \%$. The surgical findings were collected independently and compared postoperatively. There were four false negative and three false positive radiological diagnoses, the respective figures for endoscopy being two and one (Brown et al, 1973).

There can be little doubt therefore that fibreendoscopy offers an objective method of studying duodenal ulcer therapy and that selection of patients on radiological grounds alone may exclude cases with ulcer craters and include approximately $10 \%$ of cases without a duodenal ulcer. The same errors will occur additionally on follow up based solely on radiology. Fibreendoscopy has already been shown to be an acceptable procedure (Brown et al, 1972) and this is reflected in the fact that in this study all patients attended for repeat endoscopy and clinical assessment.

A much greater discrepancy was noted between endoscopic and symptomatic findings in a previous study (Brown et al, 1972). In this present study the agreement between healing and improvement of symptoms as assessed by both methods in the active group was excellent (eight out of eight patients). On the other hand three out of seven patients in the placebo group showed symptomatic evidence of improvement even though there was no change in the appearance of the ulcer crater on endoscopy (table V).

This may be explained either by a placebo effect or by postulating that ulcer pain arises from sites other than the ulcer crater itself. Epigastric pain has been produced in duodenal ulcer patients by perfusing the lower oesophagus with dilute hydrochloric acid (Earlam, 1972), although this was not substantiated in a recent similar study (Dilawari, Blendis, and Edwards, 1973). In addition the association of oesophagitis has been demonstrated in duodenal ulcer patients who had endoscopic evidence of duodenal stenosis (Salmon, 1973).

\section{TRIPOTASSIUM DICITRATO BISMUTHATE AND DUODENAL ULCER}

The results of the present study show that a colloidal bismuth compound (De-Nol) increases the rate of healing of duodenal ulcers over a short follow-up period. A large majority (nine out of 10) of the patients on active compound also obtained symptomatic relief although the relatively small number of patients studied did not allow this to reach statistical significance when compared with placebo (six out of 10). This may have been due to a placebo effect or to the natural tendency of duodenal ulcers to heal. The combination of lack of side effects in addition to promotion of ulcer healing suggests that the colloidal bismuth compound (De-Nol) has a clinical role in the management of the ambulant patient with duodenal ulcer. The increased healing rate of stress-induced gastric ulcers in rats treated with 
tripotassium dicitrato bismuthate ( 32 and $16 \mathrm{mg} /$ day) would support this suggestion.

We are grateful to the surgeons and physicians of the United Bristol Hospitals for referring patients for inclusion in this trial. We thank Mr R. Wall of Brocades (Great Britain) Ltd for the supply of tripotassium dicitrato bismuthate (De-Nol) and placebo solution. We thank Mrs E. Collins for performing the statistical analyses. P.B. acknowledges the financial help of the Medical Research Council. R.W. acknowledges the financial help of the East Anglian Regional Hospital Board.

\section{References}

Albot, G., and Boisson, J. (1969). Le traitement des ulcèrs gastroduodénaux par le sulpiride. Actualités hépato-gastro-entérol., 5, B 119-124

Baume, P. E., and Hunt, J. H. (1969). Failure of potent antacid therapy to hasten healing in chronic gastric ulcers. Aust. Ann. Med., 18, 113-116.

Bleifer, K. H., Belsky, J. L., and Bleifer, D. J. (1959). Sodium content of four antacids. New Engl. J. Med., 261, 604-605.

Borellini, D., and Milvio, C. (1969). Terapia dell'ulcera gastroduodenale, gastriti e gastroduodeniti con un farmaio antisecretino non anticolinergic (Milid). Minerva Med., 60, 10531056.

Brown, P., Salmon, P. R., Burwood, R. J., Knox, A. J., Clendinnen, G., and Read, A. E. (1973). The endoscopic, radiological, and surgical findings in chronic duodenal ulceration. (Abstr.). Gut, 14, 920.

Brown, P., Salmon, P. R., and Read, A. E. (1972a). Premedication for gastrointestinal endoscopy. (Letter). Lancet, 1, 270.

Brown, P., Salmon, P. R., Thien-Htut, and Read, A. E. (1972b). Double-blind trial of carbenoxolone sodium capsules in duodenal ulcer therapy, based on endoscopic diagnosis and follow-up. Brit. med. J., 3, 661-664.

Burnett, C. H., Commons, R. R., Albright, F., and Howard, J. E. (1949). Hypercalcemia without hypercalcuria or hypophosphatemia, calcinosis and renal insufficiency; syndrome following prolonged intake of milk, and alkali. New Engl. J. Med., 240, 787-794.

Calcraft, B., Rhodes, J., Cross, S., and Hole, D. (1973). Strengthening the gastric mucosa. (Abstr.). Gut, 14, 423.

Dilawari, J. B., Blendis, L. M., and Edwards, D. A. W. (1973). The epigastric pain in duodenal ulcer. Gut, 14, 422.

Doll, R. (1954). Medical treatment of gastric ulcer. Scot. med. J., 9, 183-196.

Doll, R., Price, A. V., Pygott, F., and Sanderson, P. H. (1956). Continuous intragastric milk drip in treatment of uncomplicated gastric ulcer. Lancet, 1, 70-73.

Earlam, R. J. (1972). Further experience with epigastric pain repro- duction test in duodenal ulceration. Brit. med. J., 2, 683-685.

Farrar, G. E., Jr., and Seifter, J. (1962). Gastrointestinal dysfunction modified by a topical anaesthetic (oxethazime). Penn. med. J., 65, 1369-1372.

Kaye, M. D., Rhodes, J., Beck, P., Sweetnam, P. M., Davies, G. T. and Evans, K. T. (1970). A controlled trial of glycopyrronium and 1-hyoscyamine in the long-term treatment of duodenal ulcer. Gut, 11, 559-566.

Lanza, F. L. (1970). An endoscopic evaluation of gastric ulcer treated with a mixture containing bismuth ammonium citrate. Curr. ther. Res., 12, 779-788.

Lawrence, J. S. (1952). Dietetic and other methods in the treatment of peptic ulcer. Lancet, 1, 482-485.

Lennard-Jones, J. E. (1961). Experimental and clinical observations on poldine in treatment of duodenal ulcer. Brit. med. J., 1, 1071-1076.

Marks, I. N., and Banks, S. (1973). Unpublished data. Quoted in Clin. Gastroent., 2, 388.

Melrose, A. G., and Pinkerton, I. W. (1961). Clinical evaluation of poldine methosulphate. Brit. med. J., 1, 1076-1078.

Newcombe, P. B., Stone, W. D., and Richardson, D. C. (1970). A double-blind trial of geranyl farnesyl acetate against placebo in the treatment of gastric ulcer. In Advance Abstracts, 4th World Congress of Gastroenterology, Copenhagen, p. 313.

Passeri, M. (1960). Osseruazioni cliniche su un nuovo agente antiulceroso deniuato dalla piperazina: l'U.B.C. 1474. Clin, ter. 19, 621-629.

Paullus, G. E. (1966). A successful management of the peptic ulcer patient in industry. Industr. Med. Surg., 35, 21-23.

Randall, R. E., Jr., Cohen, M. D., Spray, C. C., Jr., and Rossmeisl, E. C. (1964). Hypermagnesaemia in renal failure; aetiology and toxic manifestations. Ann. intern. Med., 61, 73-88.

Salmon, P. R. (1973). Endoscopic observations on the healing of duodenal ulcer. In Symposium on Peptic Ulcer, edited by $\mathbf{L}$. Demling. Schattauer, Stuttgart.

Salmon, P. R., Brown, P., Htut, T., and Read, A. E. (1972) Endoscopic examination of the duodenal bulb: clinical evaluation of forward-and side-viewing fibreoptic systems in 200 cases. Gut, 13, 170-175.

Sippy, B. W. (1915). Gastric and duodenal ulcer: medical cure by an efficient removal of gastric juice corrosion. J. Amer. med. Ass., 64, 1625-1630.

Sobotka, J. J. (1970). Peptic ulcer: a simplified ambulatory therapy. Curr. ther. Res., 12, 47-51.

Stiel, J. N., Mitchell, C. A., Radcliff, F. J., and Piper, D. W. (1967) Hypercalcemia in patients with peptic ulceration receiving large doses of calcium carbonate. Gastroenterology, 53, 900large

Sun, D. C. H., and Ryan, M. L. (1970). A controlled study on the use of propantheline and amylopectin sulphate (SN-263) for recurrences in duodenal ulcer. Gastroenterology, 58, 756-761.

Weiss, G., and Kallmeyer, J. C. (1968). A pilot trial of a colloida bismuth preparation in the treatment of peptic ulcer. $S$. Afr. med. J., 42, 317-320.

Wilson, R. (1973). To be published.

Wyllie, J. H., Ealding, W. D. P., Hesselbo, T., and Black, J. W. (1973). Inhibition of gastric secretion in man by metiamide: a new, orally active histamine $\mathbf{H}_{2}$-receptor antagonist. (Abstr.). Gut, 14, 424 